Article

\title{
Synthesis of Ball-Like Ag Nanorod Aggregates for Surface-Enhanced Raman Scattering and Catalytic Reduction
}

\author{
Wenjing Zhang ${ }^{1}$, Yin Cai ${ }^{1}$, Rui Qian ${ }^{1}$, Bo Zhao ${ }^{2}$ and Peizhi Zhu ${ }^{1, *}$ \\ 1 School of Chemistry and Chemical Engineering, Yangzhou University, Jiangsu 225002, China; \\ 15262236582@163.com (W.J.Z.); yincai1992@sina.com (Y.C.); ruiqian2016@sina.com (R.Q.) \\ 2 Jiangsu Collaborative Innovation Center of Biomedical Functional Materials and Jiangsu Key Laboratory \\ of Biofunctional Materials, School of Chemistry and Materials Science, Nanjing Normal University, \\ Nanjing 210023, China; zhaobo@njnu.edu.cn \\ * Correspondence: pzzhu@yzu.edu.cn; Tel./Fax: +86-514-87975244
}

Academic Editors: Hermenegildo García and Sergio Navalón

Received: 30 March 2016; Accepted: 18 May 2016; Published: 27 May 2016

\begin{abstract}
In this work, ball-like Ag nanorod aggregates have been synthesized via a simple seed-mediated method. These Ag mesostructures were characterized by scanning electron microscope (SEM), transmission electron microscopy (TEM), ultraviolet-visible spectroscopy (UV-Vis), and X-ray diffraction (XRD). Adding a certain amount of polyvinyl pyrrolidone (PVP) can prolong its coagulation time. These Ag nanorod aggregates exhibit effective SERS effect, evaluated by Rhodamine 6G (R6G) and doxorubicin (DOX) as probe molecules. The limit of detection (LOD) for R6G and DOX are as low as $5 \times 10^{-9} \mathrm{M}$ and $5 \times 10^{-6} \mathrm{M}$, respectively. Moreover, these Ag nanorod aggregates were found to be potential catalysts for the reduction of 4-nitrophenol (4-NP) in the presence of $\mathrm{NaBH}_{4}$.
\end{abstract}

Keywords: Ag nanorod aggregates; surface-enhanced Raman scattering; Rhodamine 6G; doxorubicin; PVP; catalytic reduction; 4-nitrophenol

\section{Introduction}

In recent years, silver nanoparticles (AgNPs) have seen broad application in areas such as catalysis [1], biomedicine [2], antimicrobial agent [3] and SERS [4,5]. As a powerful molecular fingerprinting technique, surface-enhanced Raman scattering (SERS) is a sensitive technique for trace detection [6-10]. Noble metal nanoparticles such as Ag and Au particles have been extensively explored due to their high SERS-active properties [11-17]. It is well-established that SERS activities are size and shape dependent $[18,19]$. Ag nanoparticles with complex topography have more hot-spots on surface to amplify Raman scattering of probe molecules [20,21].

Silver nanoparticles have also gained much attention for their application as a sustainable catalyst for organic transformations owing to their unique electronic properties and high surface area to volume ratio [22]. Particularly, silver nanoparticles show highly efficient catalytic activity in oxidation of methanol and ethylene [23,24], as well as reduction of nitric oxides $\left(\mathrm{NO}_{x}\right)$ [25]. Yang et al. [26] proposed that the flower-like Ag microcrystal exhibited high catalytic activity for 4-nitrophenol reduction due to their high surface area and the local electromagnetic field intensity enhancement.

Many researchers have studied numerous Ag complex structures as highly sensitive SERS substrates and catalysts [27-31]. Various methods such as chemical reduction [32,33], template process [34], and galvanic replacement [35] have been used to synthesize functional Ag nanoparticles. Using a double-reductant approach, seed-mediated method has been explored to prepare Ag nanocubes [36,37], nanowires [38], nanopolyhedron [39], and gold-Ag nanoparticles [40]. However, 
complex Ag structures possess larger surface area than single Ag nanoparticles and easily aggregate. One main method to enhance the stabilization of Ag nanoparticles is to use polymers or surfactants to modify the surface of Ag particles to prevent particles from aggregating. Being a nonionic polymer compounds, polyvinyl pyrrolidone (PVP) is often used as the capping agent to control the size and shape of the colloidal nanoparticles including Ag-NPs, Au-NPs, and Pt-NPs during the particle formation [41-43]. PVP has also been reported to be a reducing agent in the preparation for the hydroxyl end-group of the PVP polymer chain [44].

In this study, we synthesized ball-like Ag nanorod aggregates via a simple seed-mediated method without any surfactant and polymeric compound as a capping reagent in reduction. PVP was added in the last step and was used only as a stabilizer. The present approach is simple, economic and green. The SERS properties of these Ag nanorod aggregates were examined by using Rhodamine 6G (R6G) and doxorubicin (DOX) as probe molecules. In addition, its catalytic performance for the reduction of 4-nitrophenol (4-NP) in the presence of $\mathrm{NaBH}_{4}$ was also examined.

\section{Results and Discussion}

\subsection{Phase Characterization}

Ball-like Ag nanorod aggregates were synthesized via a seed-mediated method involving two reaction steps without using any surfactant and polymeric compound as a capping reagent in reduction. After adding $25 \mathrm{~mL}$ of $20 \mathrm{mM} \mathrm{AgNO}$, aggregates comprising dozens of $\mathrm{Ag}$ nanorods with a mean size of about $180 \mathrm{~nm}$ were formed (Figure 1). It is observed that these nanorods exhibit lengths of $\sim 50 \mathrm{~nm}$ and diameters of $\sim 20 \mathrm{~nm}$ (Figure 1b). The polycrystalline SEAD (selected area electron diffraction) pattern of in Figure $2 b$ confirms the diverse orientations of these nanorods in aggregates. Figure $2 b$ shows the HRTEM image of clear lattice fringes with the spacing of $0.235 \mathrm{~nm}$, which corresponds to the (111) lattice planes of the fcc-Ag [45].
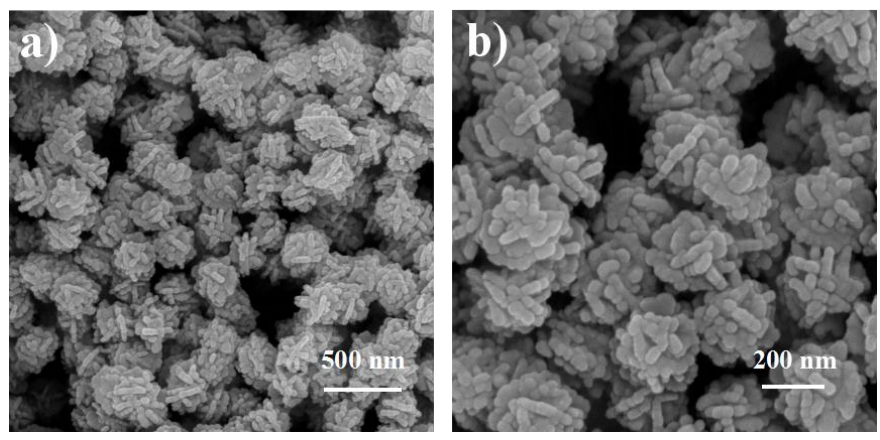

Figure 1. Scanning electron microscope (SEM) images of the ball-like Ag nanorod aggregates.
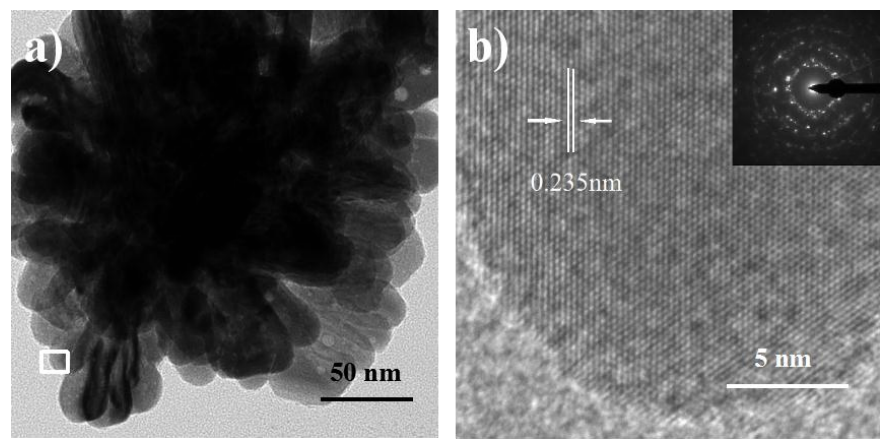

Figure 2. Transmission electron microscopy (TEM) (a) and high resolution TEM (HRTEM) (b) images of the ball-like Ag nanorod aggregates. Inset in $(\mathbf{b})$ is the selected area electron diffraction (SEAD) pattern of Ag nanorod aggregates. 


\subsection{UV-Vis Studies of Ag Nanorod Aggregates}

It is well-known that the size and shape of metal nanoparticles could affect their optical properties such as surface plasmon resonance (SPR) property [46,47]. For instance, AgNPs with complex structures usually exhibit more than one peak $[48,49]$, whereas spherical particles show only one size-dependent SPR peak [50]. As shown in Figure 3, the spectrum of Ag nanorod aggregates in aqueous solution displays two SPR bands that might indicate the information of nonspherical AgNPs. The lower wavelength band $(435 \mathrm{~nm}$ ) could be attributed to the out-of plane dipole resonance while the $693 \mathrm{~nm}$ peak (the high wavelength band) is in-plane dipole resonance [48]. In each nanorod-aggregate, the conduction electrons near each nanorod surface become delocalized and are shared amongst neighboring nanorods, which shifts the surface plasmon resonance to lower energies, moves the absorption peak to longer wavelengths and broadens the absorption spectrum.

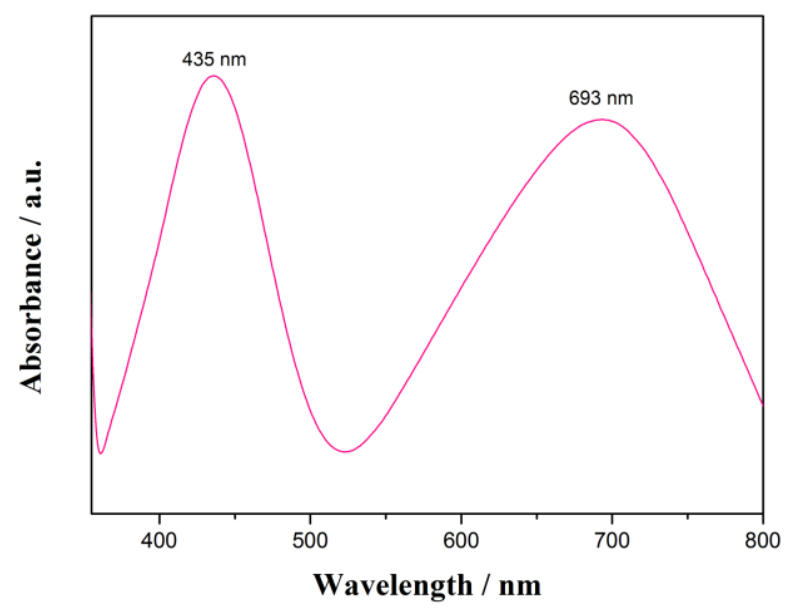

Figure 3. Ultraviolet-visible spectroscopy (UV-Vis) spectrum of the ball-like Ag nanorod aggregates.

\subsection{XRD Studies of Ag Nanorod Aggregates}

The structure of prepared ball-like Ag nanorod aggregates has been studied by X-ray diffraction (XRD) analysis. A typical XRD pattern of the particles was shown in Figure 4. The sharp peaks in XRD pattern prove the high crystallinity of Ag nanorod aggregates. The four diffraction peaks observed $38.17^{\circ}, 44.28^{\circ}, 69.45^{\circ}$, and $77.49^{\circ}$ are corresponding to (111), (200), (220), and (311) Bragg's reflections of the face-centered cubic structure of Ag, respectively (JCPDS ICDD 04-0783) [51]. There is no peak of other impurities being found from the pattern, which indicates pure Ag crystals were obtained under the present method.

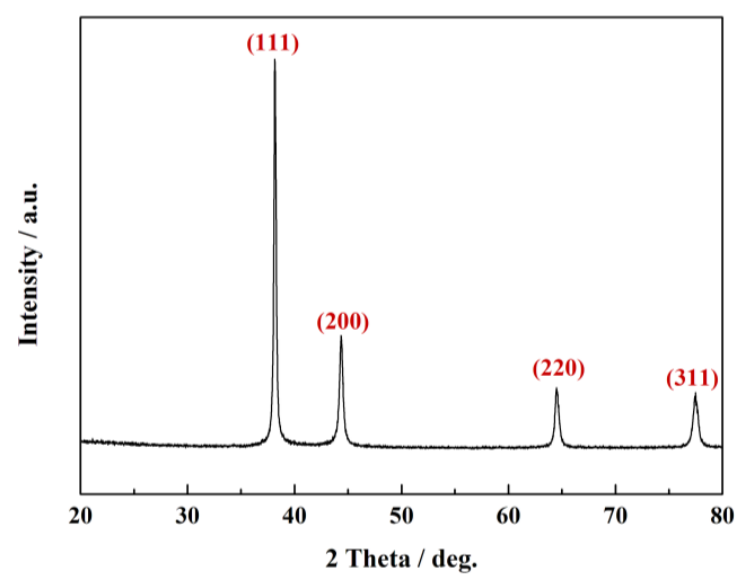

Figure 4. X-ray diffraction (XRD) pattern of the ball-like Ag nanorod aggregates. 


\subsection{Formation Mechanism of Ag Nanorod Aggregates}

The morphology of Ag nanoparticles influences their applications. In the synthesizing process of metal nanoparticles, the morphology of nanoparticle can be controlled by adjusting the reaction time, the concentration of the precursor and the reactants, and so on [30]. In our synthesis process, the reaction was almost instantaneous. Hence, the reaction rate is not main consideration. Herein, the added Ag seeds serve as the nucleation sites for the growth of the Ag nanorod aggregates. Since the ascorbic acid used as the reducing agent in second step is excessive, the anisotropic growth process could be dominated by the amount of $\mathrm{Ag}^{+}$ions, namely the concentration of $\mathrm{AgNO}_{3}$. As shown in Figure 5, when the concentration of $\mathrm{AgNO}_{3}$ varied from $5 \mathrm{mM}$ to $20 \mathrm{mM}$, Ag nanorod aggregates show similar diameters but different morphologies. At low concentration of $\mathrm{AgNO}_{3}$, a great quantity of near-spherical particles is produced. At higher concentration of $\mathrm{AgNO}_{3}$, ball-like $\mathrm{Ag}$ nanorod aggregates are formed, indicating that the concentration of $\mathrm{AgNO}_{3}$ is key factor for forming ball-like Ag nanorod aggregates [20].
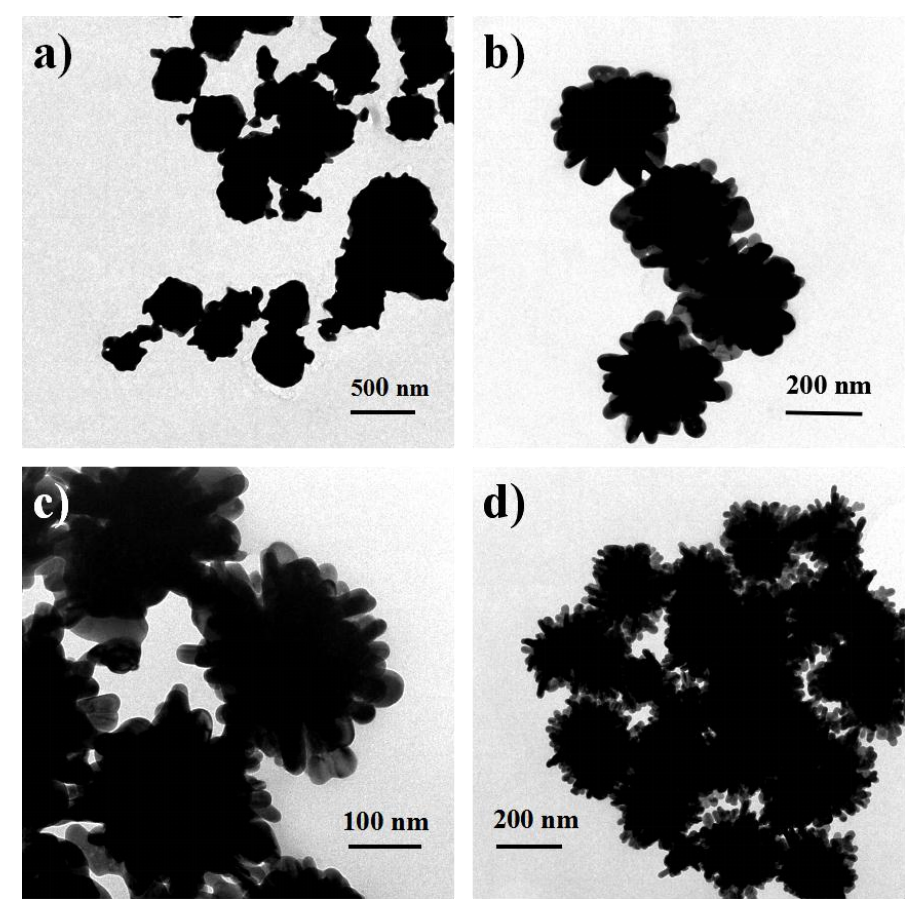

Figure 5. TEM images of the ball-like $\mathrm{Ag}$ nanorod aggregates under different concentrations of $\mathrm{AgNO}_{3}$ : (a) $5 \mathrm{mM}$; (b) $10 \mathrm{mM}$; (c) $15 \mathrm{mM}$; (d) $20 \mathrm{mM}$.

\subsection{Stability Analysis of Ag Nanorod Aggregates}

The aggregation of ball-like Ag nanorod aggregates is a concern for application that may take more time to handle with. To solve this problem, $0.005 \% \mathrm{wt} \%$ of PVP has been used in an effort to stabilize large size Ag particles in aqueous solution. Figure 6a shows the freshly obtained Ag nanorod aggregates without adding PVP (left) and with adding PVP (right). After 10 min, as shown in Figure 6b, Ag nanorod aggregates without adding PVP began to coagulate, while Ag nanorod aggregates with adding PVP remained stable due to the interaction between the particles and carbonyl groups on polymer chains of PVP. After $30 \mathrm{~min}$ (Figure 6c), Ag nanorod aggregates without adding PVP precipitated to the bottom of the bottle, and Ag nanorod aggregates with PVP begin to precipitate. However, as is shown in Figure 6d, Ag nanorod aggregates with PVP remained relatively stable even after 80 min compared with Ag nanorod aggregates without PVP. Therefore, PVP can serve as an effective stabilizer. 

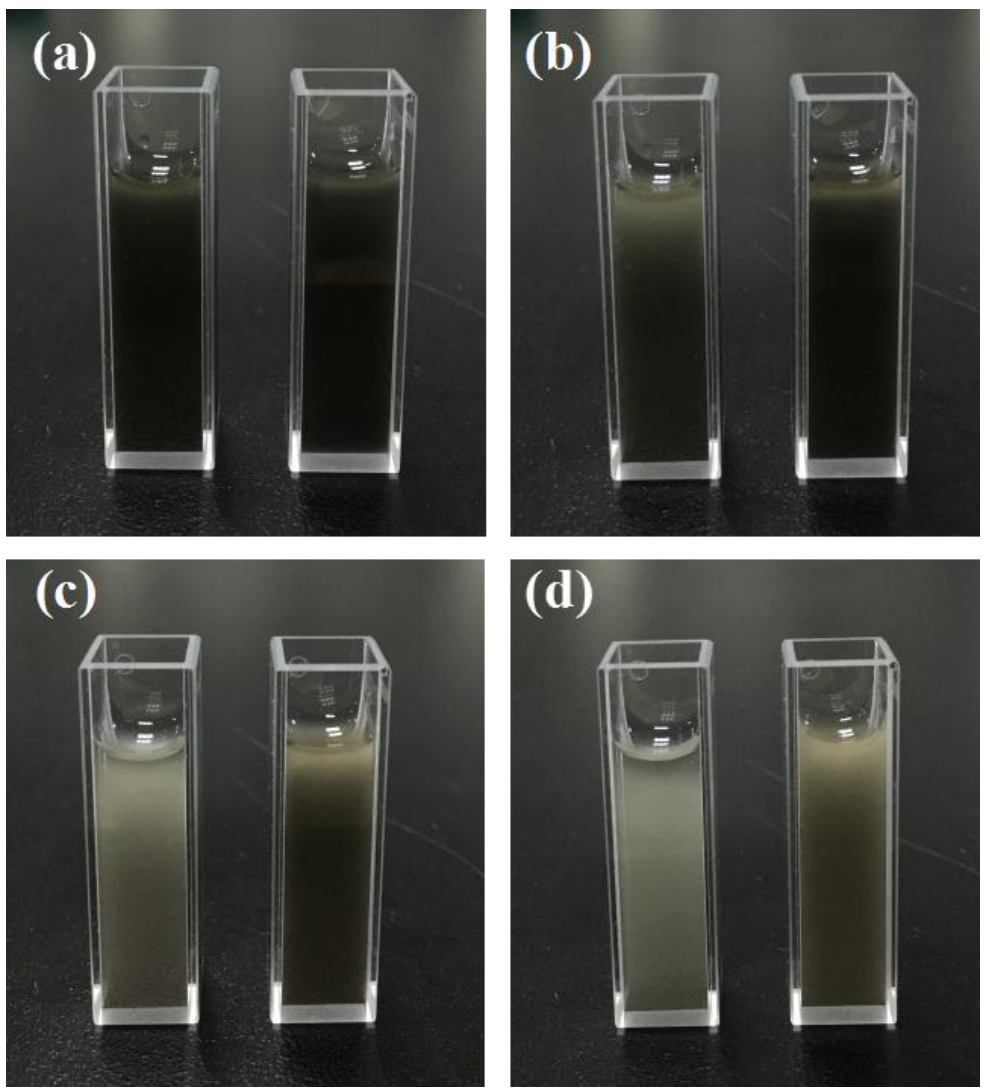

Figure 6. The coagulation condition of Ag nanorod aggregates without adding polyvinyl pyrrolidone (PVP) (left) and with adding PVP (right): (a) 0 min; (b) $10 \mathrm{~min}$; (c) $30 \mathrm{~min}$; (d) $80 \mathrm{~min}$.

\subsection{SERS Performances of Ag Nanorod Aggregates}

It is critical to determine the practical limit of detection (LOD) of probe molecules in SERS applications. Accordingly, the practical LOD of R6G absorbed on ball-like Ag nanorod aggregates coated with PVP in this work was discussed. Ag nanorod aggregates formed by self-assembled nanorods. The gaps between nanorods generate active sites or hot-spots to amplify Raman scattering of probe molecules. The Raman spectra of R6G with different concentrations absorbed on AgNPs were displayed in Figure 7. All peaks of R6G in spectra agree well with previous report [52]. PVP does not produce Raman signal at such a low concentration. The peaks at 1364, 1510 and $1650 \mathrm{~cm}^{-1}$ are attributed to the aromatic C-C stretching modes of R6G molecules, while the peak at $772 \mathrm{~cm}^{-1}$ is assigned to the $\mathrm{C}-\mathrm{H}$ out-of-plane bend mode. As shown by spectrum $\mathrm{d}\left(5 \times 10^{-9} \mathrm{M}\right)$, the characteristic bands of R6G at 570, 614, 1311, 1364, 1510, $1650 \mathrm{~cm}^{-1}$ can be still clearly detected. Therefore, the LOD for R6G absorbed on Ag nanorod aggregates was identified as $5 \times 10^{-9} \mathrm{M}$. It is difficult to calculate the enhancement factor of the R6G molecule under available experimental conditions. Hence, we calculate the relative enhancement factor for peak at $1510 \mathrm{~cm}^{-1}$ by calculating the Raman intensity ratios between $5 \times 10^{-6} \mathrm{M}$ and $5 \times 10^{-10} \mathrm{M}$. The relative enhancement factor is calculated to be $3.3 \times 10^{3}$, indicating that the flower-like nanorod aggregates could serve as effective SERS substrate. 


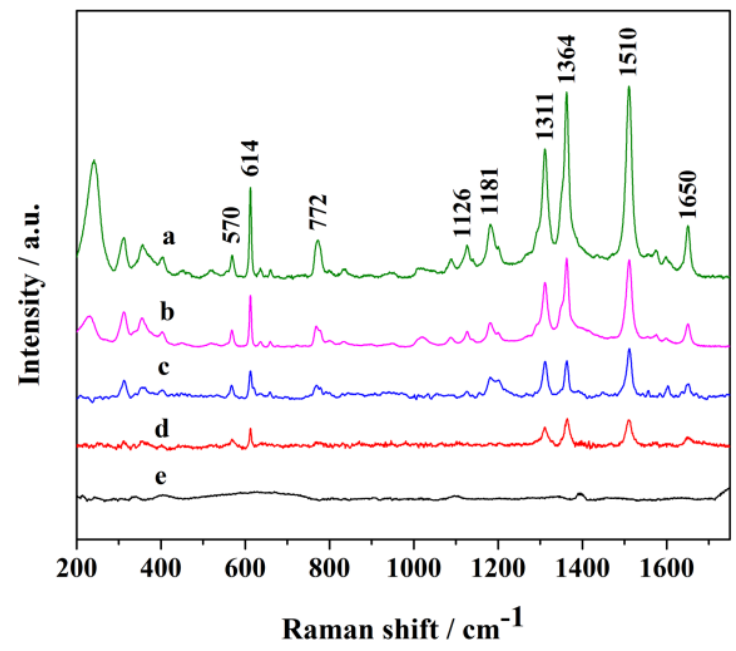

Figure 7. Raman spectra of Rhodamine 6G (R6G) at different concentrations absorbed on Ag nanorod aggregates. Spectra represent the concentrations of R6G being (a) $5 \times 10^{-6}$; (b) $5 \times 10^{-7}$; (c) $5 \times 10^{-8}$; (d) $5 \times 10^{-9}$; (e) $5 \times 10^{-10} \mathrm{M}$, respectively.

Doxorubicin is commonly used as chemotherapy drug for patients with advanced cancers. SERS has been used as a powerful tool to study DOX complexes with DNA [53] and its affinity for ferric ions. In this study, we also used DOX as probe molecule to test SERS effect of Ag nanorod aggregates. Figure 8 shows the SERS spectra of DOX at different concentrations. The band at $1639 \mathrm{~cm}^{-1}$ is assigned to the stretching mode of carbonyl groups [54]. The band at $1296 \mathrm{~cm}^{-1}$ is from C-O stretching and the two strong bands at 1244 and $1210 \mathrm{~cm}^{-1}$ can be assigned to in-plane bending motions from $\mathrm{C}-\mathrm{O}$. The weak bands at 1082 and $795 \mathrm{~cm}^{-1}$ are assigned to skeletal deformations, while $990 \mathrm{~cm}^{-1}$ is owing to ring breath modes. When the concentration of DOX reduces to $5 \times 10^{-6} \mathrm{M}$, bands at 1082,1210 , $1244,1412,1435,1456$ and $1639 \mathrm{~cm}^{-1}$ can still be clearly detected. Thus, the LOD for DOX absorbed on $\mathrm{Ag}$ nanorod aggregates was identified as $5 \times 10^{-6} \mathrm{M}$. Hence, the flower-like Ag nanorod aggregates could serve as SERS substrate for trace analysis for small drug molecules.

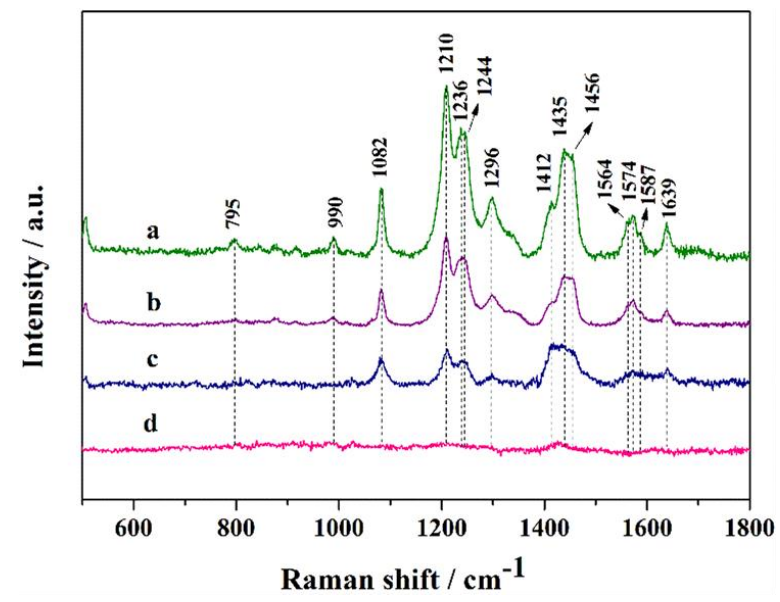

Figure 8. Raman spectra of DOX at different concentrations absorbed on Ag nanorod aggregates. Spectra represent the concentrations of DOX being (a) $5 \times 10^{-4}$; (b) $5 \times 10^{-5}$; (c) $5 \times 10^{-6}$; (d) $5 \times 10^{-7} \mathrm{M}$, respectively.

\subsection{Catalytic Reduction of 4-Nitrophenol}

The reduction of 4-nitrophenol to 4-aminophenol (4-AP) by $\mathrm{NaBH}_{4}$ was taken as a model reaction to examine the catalytic activity of the ball-like Ag nanorod aggregates. It is well known that the 
absorption peak of 4-NP with light yellow color is around $317 \mathrm{~nm}$ [55]. After the addition of freshly prepared $\mathrm{NaBH}_{4}$ solution, the light yellow turned to intense yellow, which indicates the formation of 4-nitrophenolate ion and the $\mathrm{pH}$ change from acid to basic by adding $\mathrm{NaBH}_{4}$. The catalytic process of this reaction was monitored by UV-Vis spectroscopy, Figure 9a shows the UV-Vis spectra of 4-NP reduction in the presence of $\mathrm{NaBH}_{4}$ and $0.2 \mathrm{~mL}$ of Ag nanorod aggregates. As shown in Figure 8a, absorption band at $400 \mathrm{~nm}$ is characteristic peak of the 4-nitrophenolate in the presence of only $\mathrm{NaBH}_{4}$. However, after adding $0.2 \mathrm{~mL}$ of ball-like Ag nanorod aggregates as a catalyst, a new band at around $300 \mathrm{~nm}$ emerged, indicating reduction of 4-NP to 4-AP by $\mathrm{NaBH}_{4}$ (Figure 9a). The intensity of the absorption peak at $400 \mathrm{~nm}$ gradually decreased with time, while absorption peak at $300 \mathrm{~nm}$ increased simultaneously (Figure 9a). Until the intensities of two peaks no longer changed, the reduction finished. The extinction of solution at $400 \mathrm{~nm}$ as the function of time was measured to monitor the kinetic process of the reduction. The rate constant $(K)$ was contingent upon reduction time and the linear plot of $\ln \left(A_{\mathrm{t}} / A_{0}\right)$, following pseudo-first-order kinetics (Figure $9 \mathrm{~b}$ ). The constant was calculated to be $0.02252 \mathrm{~s}^{-1}$, proving that the ball-like Ag aggregates is effective catalyst for the reduction of 4-NP. Usually, the catalytic activity is influenced by the surface area and roughness of the catalyst. Obviously, the good catalytic performance of the ball-like Ag nanorod aggregates could be attributed to their high surface area to volume ratio.
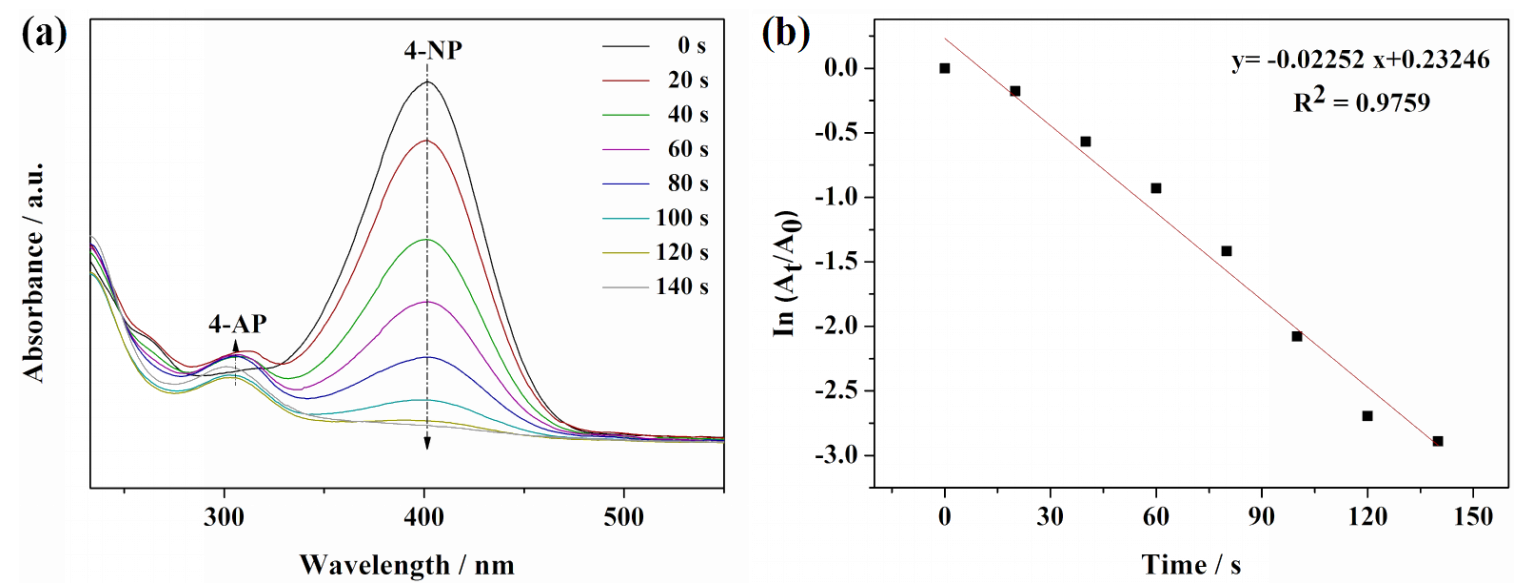

Figure 9. UV-Vis absorption spectra: (a) reduction of 4-NP by $\mathrm{NaBH}_{4}$ using Ag nanorod aggregates as catalyst; (b) The plot of $\ln \left(A_{\mathrm{t}} / A_{0}\right)$ against the reaction time for pseudo-first-order reduction kinetics of 4-NP in the presence of ball-like Ag nanorod aggregates.

\section{Materials and methods}

\subsection{Materials}

Silver nitrate $\left(\mathrm{AgNO}_{3}, 99.8 \%\right)$, tri-sodium citrate dihydrate $\left(\mathrm{C}_{6} \mathrm{H}_{5} \mathrm{Na}_{3} \mathrm{O}_{7} \cdot 2 \mathrm{H}_{2} \mathrm{O}, 99 \%\right)$, L-ascorbic acid (Vitamin C, 99.7\%), polyvinyl pyrrolidone (PVP, MW $\approx 45,000$ daltons), Rhodamine 6G, Doxorubicin hydrochloride (DOX. $\mathrm{HCl}$ ) was obtained from Fortuneibo-tech Co., Ltd (Shanghai, China). 4-nitrophenol (4-NP), sodium borohydride $\left(\mathrm{NaBH}_{4}, 96 \%\right)$ were purchased from Sinopharm Chemical Reagent Co. Ltd (Shanghai, China). All the chemicals were of analytical reagent grade and were used without further purification. All of the solutions were freshly prepared using deionized double-distilled water from a Milli-Q water purification system (Millipore Corporation, Billerica, MA, USA).

\subsection{Preparation of Ag Aggregates}

In a typical experiment, $200 \mathrm{~mL}$ of $2.5 \mathrm{mM}$ aqueous solution of $\mathrm{AgNO}_{3}$ were brought to boiling. Then, an aqueous solution of $100 \mathrm{mM}$ sodium citrate $(10 \mathrm{~mL})$ was added dropwise in to the boiled $\mathrm{AgNO}_{3}$ solution at a rate of 30 drops per min. After retained boiling for $10 \mathrm{~min}$, the colorless solution turned to yellowish and turbid colloid characteristic of the seeds formation. In order to get Ag nanorod 
aggregates, $5 \mathrm{~mL}$ of Ag seed was diluted into $35 \mathrm{~mL}$ freshly prepared L-ascorbic acid (Vitamim C) solution (5 mM). Subsequently, $25 \mathrm{~mL}$ of $\mathrm{AgNO}_{3}$ at a certain concentration was directly added. A generation of dark grey suspension indicated the formation of Ag nanorod aggregates. All the reactions were kept in the dark to avoid any photoreaction.

Later, $0.003 \mathrm{~g}$ of PVP was added to generated Ag suspension and the above mixture was performed by 5 min ultrasonic treatment. The coagulation condition of Ag particles was recorded by taking photos every $10 \mathrm{~min}$ in a while.

\subsection{Characterization Techniques}

Scanning electron microscopy (SEM, S-4800 II, Hitachi, Tokyo, Japan) and transmission electron microscopy (TEM, Philips Tecnai 12, Amsterdam, the Netherlands) was used to observe the morphologies and particle sizes of Ag nanorod aggregates. Transmission electron microscopy was performed by fixation on a 200-mesh carbon-coated copper grid. Ag nanorod aggregates were dropped onto clear glass slide and the glass slide was dried at room temperature. Then, the absorbance spectrum of Ag nanorod aggregates was measured by a UV-Vis spectroscopy (Varian Cary 500, Palo Alto, CA, USA) in the range of 350 to $800 \mathrm{~nm}$. X-ray diffraction (XRD, D8 ADVANCE, Bruker, Karlsruhe, Germany) with graphite monochromatized $\mathrm{Cu} \mathrm{K} \alpha$ radiation operating at $40 \mathrm{kV}$ and $40 \mathrm{~mA}$ at room temperature in the range $2 \theta\left(20^{\circ} \leqslant 2 \theta \leqslant 80^{\circ}\right)$ was utilized to determine the crystalline structure of the samples.

\subsection{SERS Performance of R6G and DOX on Ag Nanorod Aggregates}

To determine the LOD for R6G and DOX, a series of concentrations of R6G and DOX in water were detected using SERS Ag nanorod aggregates coated with PVP. SERS spectra were recorded with a Confocal Raman spectrometer (DXR, GX-PT-2412, Thermo, Waltham, MA, USA) with 780 nm line of a He-Ne laser as excitation wavelength. The laser power at the samples was $24 \mathrm{~mW}$ and the data acquisition time was $60 \mathrm{~s}$. R6G and DOX was used as probe molecules. $200 \mu \mathrm{L}$ of R6G at concentration of $5 \times 10^{-6}, 5 \times 10^{-7}, 5 \times 10^{-8}, 5 \times 10^{-9}, 5 \times 10^{-10} \mathrm{M}$ were mixed with $200 \mu \mathrm{L}$ of Ag nanorod aggregates suspension at concentration of $8.3 \mathrm{mM}$. $200 \mu \mathrm{L}$ of DOX at concentration of $5 \times 10^{-4}$, $5 \times 10^{-5}, 5 \times 10^{-6}, 5 \times 10^{-7} \mathrm{M}$ were mixed with $200 \mu \mathrm{L}$ of $\mathrm{Ag}$ nanorod aggregates suspension at concentration of $8.3 \mathrm{mM}$. The spectra were obtained in solution-phase after mixing for an hour to make sure that dye molecules could absorb on the surface of AgNPs sufficiently at room temperature.

\subsection{Catalytic Reduction}

In a typical run for the reduction of $4-\mathrm{NP}$ by $\mathrm{NaBH}_{4}, 0.05 \mathrm{~mL}$ of fresh solution of 4-NP $(1 \mathrm{mM})$ was introduced into $2 \mathrm{~mL}$ of $\mathrm{NaBH}_{4}(0.1 \mathrm{M})$ solution. Then, $0.2 \mathrm{~mL}$ of $\mathrm{Ag}$ nanorod aggregates $(1 \mathrm{mM})$ was added to the above mixed solution. Then, with the addition of $2.75 \mathrm{~mL}$ of ultrapure water, the total volume of the reaction system was $5.00 \mathrm{~mL}$. Set a blank group, the reaction system is same as the above system except that the Ag nanorod aggregates solution was replaced by ultrapure water. After the addition of $0.2 \mathrm{~mL}$ of Ag nanorod aggregates catalyst, scanning 600-250 nm band immediately in order to monitor the spectra of the 4-NP reduction in the presence of $\mathrm{NaBH}_{4}$ and $\mathrm{Ag}$ nanorod aggregates solution by using UV-visible spectrophotometric monitoring instrument.

\section{Conclusions}

In summary, ball-like Ag nanorod aggregates with a mean size of $180 \mathrm{~nm}$ were synthesized by a seed-mediated approach, which is simple, economic and green. The polyvinyl pyrrolidone (PVP) was used to enhance the stability of obtained Ag nanorod aggregates in aqueous solution for SERS and catalytic experiment. Ag nanorod aggregates exhibit effective and reproducible SERS effect, evaluated by R6G as probe molecules. The limit of detection (LOD) for R6G and DOX are as low as $5 \times 10^{-9}$ $\mathrm{M}$ and $5 \times 10^{-6} \mathrm{M}$, respectively, which shows promising application for trace detection of small 
molecules. These Ag nanorod aggregates possess large surface area and porous surface morphology and could serve as a potential catalyst for the reduction of 4-NP in the presence of $\mathrm{NaBH}_{4}$.

Acknowledgments: This work was supported by Jiangsu Province for specially appointed professorship to Peizhi Zhu, research funds from Yangzhou University, research funds from Liuda Rencai Gaofeng, the Technology Support Program of Science and Technology Department of Jiangsu Province (BE2015703), the Jiangsu agricultural science and Technology Innovation Fund Project (CX(14)2127), the support from the Testing Center of Yangzhou University, and A Project Funded by the Priority Academic Program Development of Jiangsu Higher Education Institutions.

Author Contributions: Peizhi Zhu proposed the topic of this study and designed the experiments. Wenjing Zhang, Yin Cai and Rui Qian performed the synthesis, characterization, and analysis of AgNPs and did study on its catalytic activities. Bo Zhao performed and analyzed the SERS effects and drafted the manuscript. Peizhi Zhu and Wenjing Zhang analyzed the data and wrote the final manuscript. All authors read and approved the final manuscript.

Conflicts of Interest: The authors declare no conflict of interest.

\section{References}

1. Dasa, S.; Dhar, B.B. Green synthesis of noble metal nanoparticles using cysteine-modified silk fibroin: Catalysis and antibacterial activity. RSC Adv. 2014, 4, 46285-46292. [CrossRef]

2. Mi, S.N.; Jun, B.H.; Kim, S.; Kang, H.; Woo, M.A.; Minai-Tehrani, A.; Kim, J.E.; Kim, J.; Park, J.; Lim, H.T.; et al. Magnetic surface-enhanced Raman spectroscopic (M-SERS) dots for the identification of bronchioalveolar stem cells in normal and lung cancer mice. Biomaterials 2009, 30, 3915-3925.

3. Reithofer, M.R.; Lakshmanan, A.; Ping, A.T.K.; Jia, M.C.; Hauser, C.A.E. In situ synthesis of size-controlled, stable silver nanoparticles within ultrashort peptide hydrogels and their anti-bacterial properties. Biomaterials 2014, 35, 7535-7542. [CrossRef] [PubMed]

4. Wang, Y.L.; Lee, K.; Irudayaraj, J. SERS aptasensor from nanorod-nanoparticle junction for protein detection. Chem. Commun. 2010, 46, 613-615. [CrossRef] [PubMed]

5. Shafer-Peltier, K.E.; Haynes, C.L.; Glucksberg, M.R.; van Duyne, R.P. Toward a glucose biosensor based on surface-enhanced Raman scattering. J. Am. Chem. Soc. 2003, 125, 588-593. [CrossRef] [PubMed]

6. Hou, M.J.; Huang, Y.; Ma, L.W.; Zhang, Z.J. Sensitivity and reusability of $\mathrm{SiO}_{2} \mathrm{NRs@AuNPs} \mathrm{SERS} \mathrm{substrate}$ in trace monochlorobiphenyl detection. Nanoscale Res. Lett. 2015, 10. [CrossRef] [PubMed]

7. Li, J.M.; Ma, W.F.; Wei, C.; You, L.J.; Guo, J.; Hu, J.; Wang, C.C. Detecting trace melamine in solution by SERS using Ag nanoparticle coated poly(styrene-co-acrylic acid) nanospheres as novel active substrates. Langmuir 2011, 27, 14539-14544. [CrossRef] [PubMed]

8. Li, J.F.; Huang, Y.F.; Ding, Y.; Yang, Z.L.; Li, S.B.; Zhou, X.S.; Fan, F.R.; Zhang, W.; Zhou, Z.Y.; Wu, Y.D.; et al. Shell-isolated nanoparticle-enhanced Raman spectroscopy. Nature 2010, 464, 392-395. [CrossRef] [PubMed]

9. Cheng, M.L.; Tsai, B.C.; Yang, J. Silver nanoparticle-treated filter paper as a highly sensitive surface-enhanced Raman scattering (SERS) substrate for detection of tyrosine in aqueous solution. Anal. Chim. Acta 2011, 708, 89-96. [CrossRef] [PubMed]

10. Maiti, K.K.; Dinish, U.S.; Samanta, A.; Vendrell, M.; Soh, K.S.; Park, S.J.; Olivo, M.; Chang, Y.T. Multiplex targeted in vivo cancer detection using sensitive near-infrared SERS nanotags. Nano Today 2012, 7, 85-93. [CrossRef]

11. Herrera, G.M.; Padilla, A.C.; Hernandez-Rivera, S.P. Surface enhanced Raman scattering (SERS) studies of gold and silver nanoparticles prepared by laser ablation. Nanomaterials 2013, 3, 158-172. [CrossRef]

12. Li, Y.S.; Cheng, Y.Y.; Xu, L.P.; Du, H.W.; Zhang, P.X.; Wen, Y.Q.; Zhang, X.J. A nanostructured SERS switch based on molecular beacon-controlled assembly of gold nanoparticles. Nanomaterials 2016, 6. [CrossRef]

13. Onuegbu, J.; Fu, A.; Glembocki, O.; Pokes, S.; Alexson, D.; Hosten, C.M. Investigation of chemically modified barium titanate beads as surface-enhanced Raman scattering (SERS) active substrates for the detection of benzene thiol, 1,2-benzene dithiol, and rhodamine 6G. Spectrochim. Acta A 2011, 79. [CrossRef] [PubMed]

14. Fateixa, S.; Pinheiro, P.C.; Nogueira, H.I.S.; Trindade, T. Composite blends of gold nanorods and poly(t-butylacrylate) beads as new substrates for SERS. Spectrochim. Acta A 2013, 113. [CrossRef] [PubMed]

15. Li, S.Q.; Liu, L.; Hu, J.B. An approach for fabricating self-assembled monolayer of gold nanoparticles on $\mathrm{NH}^{2+}$ ion implantation modified indium tin oxide as the SERS-active substrate. Spectrochim. Acta A 2012, 86, 533-537. [CrossRef] [PubMed] 
16. Philip, D.; Gopchandran, K.G.; Unni, C.; Nissamudeen, K.M. Synthesis, characterization and SERS activity of Au-Ag nanorods. Spectrochim. Acta A 2008, 70, 780-784. [CrossRef] [PubMed]

17. Yang, L.B.; Qin, X.Y.; Gong, M.D.; Jiang, X.; Yang, M.; Li, X.L.; Li, G.Z. Improving surface-enhanced Raman scattering properties of $\mathrm{TiO}_{2}$ nanoparticles by metal Co doping. Spectrochim. Acta A 2014, 123, 224-229. [CrossRef] [PubMed]

18. Wu, W.J.; Wu, M.Z.; Sun, Z.Q.; Li, G.; Ma, Y.Q.; Liu, X.S.; Wang, X.F.; Chen, X.S. Morphology controllable synthesis of silver nanoparticles: Optical properties study and SERS application. J. Alloy.Compd. 2013, 579, 117-123. [CrossRef]

19. Sun, L.L.; Song, Y.H.; Wang, L.; Guo, C.L.; Sun, Y.J.; Liu, Z.L.; Li, Z. Ethanol-induced formation of silver nanoparticle aggregates for highly active SERS substrates and application in DNA detection. J. Phys. Chem. C 2008, 112, 1415-1422. [CrossRef]

20. Nhung, T.T.; Lee, S.W. Green synthesis of asymmetrically textured silver meso-flowers (AgMFs) as highly sensitive SERS substrates. ACS Appl. Mater. Interfaces 2014, 6, 21335-21345. [CrossRef] [PubMed]

21. Zhang, M.F.; Zhao, A.W.; Sun, H.H.; Guo, H.Y.; Wang, D.P.; Li, D.; Gan, Z.B.; Tao, W.Y. Rapid, large-scale, sonochemical synthesis of 3D nanotextured silver microflowers as highly efficient SERS substrates. J. Mater. Chem. 2011, 21, 18817-18824. [CrossRef]

22. Dao, A.T.N.; Mott, D.M.; Higashimine, K.; Maenosono, S. Enhanced electronic properties of Pt@Ag heterostructured nanoparticles. Sensors 2013, 13, 7813-7826. [CrossRef] [PubMed]

23. Qayyum, E.; Castillo, V.A.; Warrington, K.; Barakat, M.A.; Kuhn, J.N. Methanol oxidation over silica-supported Pt and Ag nanoparticles: Toward selective production of hydrogen and carbon dioxide. Catal. Commum. 2012, 28, 128-133. [CrossRef]

24. Lippits, M.J.; Nieuwenhuys, B.E. Direct conversion of ethanol into ethylene oxide on copper and silver nanoparticles: Effect of addition of $\mathrm{CeO}_{x}$ and $\mathrm{Li}_{2} \mathrm{O}$. Catal. Today 2010, 154, 127-132. [CrossRef]

25. Wunder, S.; Polzer, F.; Lu, Y.; Mei, Y.; Ballauff, M. Kinetic analysis of catalytic reduction of 4-nitrophenol by metallic nanoparticles immobilized in spherical polyelectrolyte brushes. J. Phys. Chem. C 2010, 114, 8814-8820. [CrossRef]

26. Yang, J.H.; Cao, B.B.; Li, H.Q.; Liu, B. Investigation of the catalysis and SERS properties of flower-like and hierarchical silver microcrystals. J. Nanopart. Res. 2014, 16. [CrossRef]

27. Sajanlal, P.R.; Pradeep, T. Mesoflowers: A new class of highly efficient surface-enhanced Raman active and infrared-absorbing materials. Nano. Res. 2009, 2, 306-320. [CrossRef]

28. Xia, J.R.; Wei, R.; Wu, Y.M.; Li, W.H.; Yang, L.N.; Yang, D.H.; Song, P. Synthesis of large flower-like substrates for surface-enhanced Raman scattering. Chem. Eng. J. 2014, 244, 252-257. [CrossRef]

29. Kar, S.; Desmonda, C.; Tai, Y. Synthesis of SERS-active stable anisotropic silver nanostructures constituted by self-assembly of multiple silver nanopetals. Plasmonics 2014, 9, 485-492. [CrossRef]

30. Zhou, N.; Li, D.S.; Yang, D.R. Morphology and composition controlled synthesis of flower-like silver nanostructures. Nanoscale Res. Lett. 2014, 9. [CrossRef] [PubMed]

31. Xu, M.W.; Zhang, Y. Seed-mediated approach for the size-controlled synthesis of flower-like Ag mesostructures. Mater. Lett. 2014, 130, 9-13. [CrossRef]

32. Tang, B.; Xu, S.P.; Jian, X.G.; Tao, J.L.; Xu, W.Q. Real-time, in-situ, extinction spectroscopy studies on silver-nanoseed formation. Appl. Spectrosc. 2010, 64, 1407-1415. [CrossRef] [PubMed]

33. Mahl, D.; Diendirf, J.; Ristig, S.; Greulich, C.; Li, Z.A.; Farle, M.; Köller, M.; Epple, M. Silver, gold, and alloyed silver-gold nanoparticles: Characterization and comparative cell-biologic action. J. Nanopart. Res. 2012, 14. [CrossRef]

34. Noh, J.H.; Meijboom, R. Catalytic evaluation of dendrimer-templated Pd nanoparticles in the reduction of 4-nitrophenol using Langmuir-Hinshelwood kinetics. Appl. Surf. Sci. 2014, 320, 400-413. [CrossRef]

35. Gutés, A.; Carraro, C.; Maboudian, R. Silver dendrites from galvanic displacement on commercial aluminum foil as an effective SERS substrate. J. Am. Chem. Soc. 2010, 132, 1476-1477. [CrossRef] [PubMed]

36. Zhang, Q.; Li, W.Y.; Moran, C.; Zeng, J.; Chen, J.Y.; Wen, L.P.; Xia, Y.N. Seed-mediated synthesis of Ag nanocubes with controllable edge lengths in the range of 30-200 $\mathrm{nm}$ and comparison of their optical properties. J. Am. Chem. Soc. 2010, 132, 11372-11378. [CrossRef] [PubMed]

37. Zhang, L.; Wang, Y.; Tong, L.M.; Xia, Y.N. Seed-mediated synthesis of silver nanocrystals with controlled sizes and shapes in droplet microreactors separated by air. Langmuir 2013, 29, 15719-15725. [CrossRef] [PubMed] 
38. Guo, S.J.; Zhang, S.; Su, D.; Sun, S.H. Seed-mediated synthesis of core/shell FePtM/FePt $(\mathrm{M}=\mathrm{Pd}, \mathrm{Au})$ nanowires and their electrocatalysis for oxygen reduction reaction. J. Am. Chem. Soc. 2013, 135, 13879-13884. [CrossRef] [PubMed]

39. Xia, X.H.; Zeng, J.; Oetjen, L.K.; Li, Q.G.; Xia, Y.N. Quantitative analysis of the role played by poly(vinylpyrrolidone) in seed-mediated growth of Ag nanocrystals. J. Am. Chem. Soc. 2012, 134, 1793-1801. [CrossRef] [PubMed]

40. Mcgilvray, K.L.; Fasciani, C.; Bueno-Alejo, C.J.; Schwartz-Narbonne, R.; Scaiano, J.C. Photochemical strategies for the seed-mediated growth of gold and gold-silver nanoparticles. Langmuir 2012, 28, 16148-16155. [CrossRef] [PubMed]

41. Liang, H.Y.; Wang, W.Z.; Huang, Y.Z.; Zhang, S.P.; Wei, H.; Xu, H.X. Controlled synthesis of uniform silver nanospheres. J. Phys. Chem. C 2010, 114, 7427-7431. [CrossRef]

42. Tang, X.L.; Jiang, P.; Ge, G.L.; Tsuji, M.; Xie, S.S.; Guo, Y.J. Poly(N-vinyl-2-pyrrolidone) (PVP)-capped dendritic gold nanoparticles by a one-step hydrothermal route and their high SERS effect. Langmuir 2008, 24, 1763-1768. [CrossRef] [PubMed]

43. Hossain, M.J.; Tsunoyama, H.; Yamauchi, M.; Ichikuni, N.; Tsukuda, T. High-yield synthesis of PVP-stabilized small Pt clusters by microfluidic method. Catal. Today 2012, 183, 101-107. [CrossRef]

44. Wu, C.W.; Mosher, B.P.; Lyons, K.; Zeng, T.F. Reducing ability and mechanism for polyvinylpyrrolidone (PVP) in silver nanoparticles synthesis. J. Nanosci. Nanotechnol. 2010, 10, 2342-2347. [CrossRef] [PubMed]

45. Wang, A.L.; Yin, H.B.; Ren, M.; Liu, Y.M.; Jiang, T.S. Synergistic effect of silver seeds and organic modifiers on the morphology evolution mechanism of silver nanoparticles. Appl. Surf. Sci. 2008, 254, 6527-6536. [CrossRef]

46. Rashid, M.H.; Mandal, T.K. Synthesis and catalytic application of nanostructured silver dendrites. J. Phys. Chem. C 2007, 111, 16750-16760. [CrossRef]

47. Mayer, K.M.; Hafner, J.H. Localized surface plasmon resonance sensors. Chem. Rev. 2011, 111, 3828-3857. [CrossRef] [PubMed]

48. Chen, S.H.; Carroll, D.L. Synthesis and characterization of truncated triangular silver nanoplates. Nano Lett. 2002, 2, 1003-1007. [CrossRef]

49. Zou, X.Q.; Ying, E.B.; Dong, S.J. Preparation of novel silver-gold bimetallic nanostructures by seeding with silver nanoplates and application in surface-enhanced Raman scattering. J. Colloid Interf. Sci. 2007, 306, 307-315. [CrossRef] [PubMed]

50. Pillai, Z.S.; Kamat, P.V. What factors control the size and shape of silver nanoparticles in the citrate ion reduction method? J. Phys. Chem. B 2004, 108, 945-951. [CrossRef]

51. Ahmad, M.B.; Lim, J.J.; Shameli, K.; Ibrahim, N.A.; Tay, M.Y. Synthesis of silver nanoparticles in chitosan, gelatin and chitosan/gelatin bionanocomposites by a chemical reducing agent and their characterization. Molecules 2011, 16, 7237-7248. [CrossRef] [PubMed]

52. Li, Y.X.; Zhang, K.; Zhao, J.J.; Ji, J.; Ji, C.; Liu, B.H. A three-dimensional silver nanoparticles decorated plasmonic paper strip for SERS detection of low-abundance molecules. Talanta 2016, 147, 493-500. [CrossRef] [PubMed]

53. Beljebbar, A.; Sockalingum, G.D.; Angiboust, J.F.; Manfait, M. Comparative FT SERS, resonance Raman and SERRS studies of doxorubicin and its complex with DNA. Spectrochim. Acta A 1995, 51, 2083-2090. [CrossRef]

54. Gautier, J.; Munnier, E.; Douziech-Eyrolles, L.; Paillard, A.; Dubois, P.; Chourpa, L. SERS spectroscopic approach to study doxorubicin complexes with $\mathrm{Fe}^{2+}$ ions and drug release from SPION-based nanocarriers. Analyst 2013, 138, 7354-7361. [CrossRef] [PubMed]

55. Baruah, B.; Gabriel, G.J.; Akbashev, M.J.; Booher, M.E. Facile synthesis of silver nanoparticles stabilized by cationic polynorbornenes and their catalytic activity in 4-nitrophenol reduction. Langmuir 2013, 29, 4225-4234. [CrossRef] [PubMed]

(C) 2016 by the authors; licensee MDPI, Basel, Switzerland. This article is an open access article distributed under the terms and conditions of the Creative Commons Attribution (CC-BY) license (http://creativecommons.org/licenses/by/4.0/). 